using existing laws. The issue remains among the greatest challenges in tobacco control and TobReg has done us a great service by moving the agenda into a spotlight where it deserves prolonged debate.

\section{Competing interests: None.}

Tobacco Control 2008;17:73-74.

doi:10.1136/tc.2008.025106

\section{REFERENCES}

1. World Health Organization. WHO Report on the Global Tobacco Epidemic 2008. http://www.who.int/ tobacco/mpower/mpower report full 2008.pdf. laccessed 26 February 2008)

2. Gunja M, Wayne GF, Landman A, et al. The case for fire safe cigarettes made through industry documents. Tob Control 2002;11:346-53.

3. Burns D, Dybing E, Gray N, et al. Mandated lowering of toxicants in cigarette smoke: a description of the WHO TobReg proposal. Tob Control 2008;17:132-41.

4. Bialous SA, Yach D. Whose standard is it, anyway? How the tobacco industry determines the International Organization for Standardization (ISO) standards for tobacco and tobacco products. Tob Control 2001:10:96-104.

5. Martuzzi M, Bertollini R. The precautionary principle science and human health protection. Int J Occup Med Environ Health 2004;17:43-6.
6. Chapman S, Freeman B. Markers of the denormalisation of smoking and the tobacco industry. Tob Control 2008;17:25-31.

7. Freeman B, Chapman SLO. Tobacco promotion invades new media. Lancet Oncol 2007;8:973-4.

8. Borland R. A strategy for controlling the marketing of tobacco products: a regulated market model. Tob Control 2003;12:374-82

9. Callard C, Thompson D, Collishaw N. Transforming the tobacco market: why the supply of cigarettes should be transferred from for-profit corporations to non-profit enterprises with a public health mandate. Tob Control 2005:14:278-83.

10. Liberman $\mathbf{J}$. The future of tobacco regulation: a response to a proposal for fundamental institutional change. Tob Control 2006;15:333-8.

\title{
The proposed tobacco regulation: the triumph of hope over experience?
}

\section{Lynn T Kozlowski}

In tobacco control, we try to reduce death and disability from tobacco use. The job of TobReg is a tough one that its authors think someone should and can do. They may be right, but I am not yet convinced.

The industry has been faulted for its secrecy. And the absence of governmental regulation and the principles of trade secrets have supported this secrecy. Via TobReg, some of the best and the brightest in tobacco control propose extensive secrecy themselves with respect to what is learned or even thought about the toxic yields of cigarettes and possible reductions in those toxic yields. Why would those committed to improving public health want no public claims for individual products arising from systematic attempts to make cigarettes less dangerous? This could be a good idea for several reasons (in no special order): (1) the toxicant reductions may not actually produce any risk reduction to individuals; (2) the toxicant reductions may produce such small reductions in risks to individuals that they do not importantly reduce risk; or (3) the perception by smokers of reduced risks may be acted on by smokers in a way that reduces smoking cessation or promotes recruitment to smoking. Any or all of these outcomes would be seen as unfortunate for tobacco control and the TobReg effort.

Correspondence to: Lynn T Kozlowski, School of Public Health and Health Professions, University at Buffalo,

State University of New York, Buffalo, New York, USA; LK22@buffalo.edu
The many proposed controls of public knowledge or opinion on the regulatory system are "the responsibility of the regulatory structure to monitor". Really? What governmentally-budgeted thought police could truly monitor or correct the accuracy of news reports or editorials or blogs in the modern world? This proposal would take responsibility for controlling smokers' understandings and interpretations about the risks of tobacco products. And if "regulators" find consumer views are not as they wish about tobacco products or changes in tobacco products, "regulators should then pursue whatever corrective action is necessary to prevent consumers from being misled". Such power would be the unrealisable dreams of the most powerful, paternalistic totalitarian state. Do we imagine that, for example, an investigative reporter or university student somewhere in the world would not readily find the present TobReg report in Tobacco Control as an element of the public, scientific record or any of the various other published reports that will discuss and debate the TobReg proposal in the coming months or years? I believe that the "regulators" will not truly have the superpowers that are asserted-not only because of budgetary constraints, but also because the understandings and interpretations of human beings will be more often out of their reach.

Credible, organised public health efforts to make cigarettes safer will likely come to be noticed by the public, and the public will likely interpret that cigarettes as a class are becoming less dangerous. In general, the traditions of the tar and nicotine testing business around the world have tried to have it "both ways", by not officially saying that lower tar cigarettes-as a class-are safer, while permitting that inference to be drawn. In a sense, the TobReg program would allow similar inferences of reduced risk to be drawn, even though direct promotional claims of reduced risk or lower toxicant levels about specific brands would be forbidden, and even though many efforts are proposed to control the public's thoughts and understandings about tobacco products. If it ever got to legal testimony on the matter, the "regulators" themselves would be forced to acknowledge that the reductions in toxicants were intended to reduce product risks and that they may be doing just that. TobReg-type systems could contribute to the normalisation of the cigarette industry and add to the years of cigarette sales. This stateof-the-art, tobacco-control-sanctioned effort to reduce risks could cause reasonable authorities to want to see how much risks are reduced. This will take time and more research.

Once again firing up the chromatographs in the service of policy may not result in progress in tobacco control. The focus on reduced exposure cigarettes as a tool of tobacco control represents, as Samuel Johnson said of second marriages, the triumph of hope over experience. We might better consider focusing on characterising cross-product comparisons and the likely risk reduction arising from smokeless tobacco and medicinal nicotine products, placing all cigarettes squarely in the category of being too dangerous to keep tinkering with. ${ }^{1}$ Rather than hoping for secrecy and some imagined ability to repair the ill-thinking arising from any leaked information, we would be better to continue to work on how meaningful 
differential risk to health can be effectively and accurately communicated. ${ }^{23}$

Should cigarettes be transformed according to the TobReg analytical procedures? Probably. But the communications plan for this should make it clear that this will likely have a small effect on the individual and population risks of smoking. ${ }^{4}$ We should prepare to compete in the open exchange of health information, rather than assume no discourse should or will occur and wrong-thoughts can be controlled. The tools of making the most dangerous tobacco products the most expensive and hardest to use will remain crucial to tobacco control.

Competing interests: LTK receives research funding from the US National Cancer Institute, and has been funded by the Robert Wood Johnson Foundation. LTK receives no funding from the tobacco industry. He has received honoraria and hospitality from drug companies involved in production of tobacco-dependence treatments, and agencies involved in promoting health (e.g., Robert Wood Johnson Foundation, NIH). He has worked as a paid expert witness in litigation for plaintiffs against tobacco companies.

Tobacco Control 2008;17:74-75. doi:10.1136/tc.2008.025155

\section{REFERENCES}

1. Kozlowski LT. Effect of smokeless tobacco product marketing and use on population harm from tobacco use policy perspective for tobacco-risk reduction. Am J Prev Med 2007;33(6 Suppl):S379-86.

2. Kozlowski LT, Edwards BQ. "Not safe" is not enough: smokers have a right to know more than there is no safe tobacco product. Tob Control 2005;14/Suppl 2):ii3-7.

3. Dollar KM, Mix JM, Kozlowski LT. Little cigars, big cigars: omissions and commissions of harm and harm reduction information on the internet. Nicotine Tob Res: in press.

4. Kozlowski LT, Strasser AA, Giovino GA, et al. Applying the risk/use equilibrium: use medicinal nicotine now for harm reduction. Tob Control 2001:10:201-3

\section{Electronic pages}

\section{Tobacco Control Online: http://tc.bmj.com}

The following electronic only article is published in conjunction with this issue of Tobacco Control.

\section{A PLEASURE AMONG FRIENDS: HOW NARGHILE (WATERPIPE) SMOKING DIFFERS FROM CIGARETTE SMOKING IN SYRIA F Hammal, J Mock, K D Ward, T Eissenberg, W Maziak}

Background: Throughout the Eastern Mediterranean region (EMR), tobacco is used primarily in two forms: cigarette smoking and narghile (water pipe) smoking.

Objective: To explore whether narghile smokers are different from cigarette smokers in how their smoking habits are embedded in their everyday lives.

Methods: One-to-one interviews with 16 adult narghile smokers and 16 adult cigarette smokers about their feelings, experiences and beliefs regarding their initiation, use patterns, and attempts to quit.

Findings: Narghile smokers found that narghile was a pleasurable social experience embedded in cultural rituals. By contrast, cigarette smokers saw their cigarette smoking as a mundane, oppressive, personal addiction. Narghile smokers generally started in their 20s and found that smoking narghile fostered a sense of togetherness and cultural identity, while cigarette smokers started in their early teens, males having started to becoming a "real man". Unlike cigarette smokers who felt stigmatised, narghile smokers generally felt that smoking narghile was socially accepted. Cigarette smokers believed that cigarettes were harmful to their health and harmful to those around them, but narghile smokers believed smoking narghile was relatively harmless to themselves or to others. Unlike cigarette smokers who used cigarettes to manage stress, narghile smokers used narghile for entertainment, leisure, and escape. However, frequent narghile smokers confessed that they felt addicted in much the same way as cigarette smokers. Cigarette smokers and narghile smokers viewed quitting as a matter of will and conviction. Most cigarette smokers had tried to quit. Very few narghile smokers had ever tried to quit, and most were not interested in quitting. Disturbingly, some cigarette smokers had tried to quit cigarettes by switching to smoking narghile, but later relapsed to smoking cigarettes.

Conclusions: This exploratory study suggests that Syrian narghile smokers are different from Syrian cigarette smokers in their perceptions and beliefs about their smoking, and in their smoking patterns and lived experiences with tobacco. Our findings indicate that further in-depth research is need in the EMR to understand both modes of smoking to develop effective modespecific prevention and cessation approaches. This study also raises concerns about a possible pattern where cigarette smokers are using narghile as a method for quitting cigarettes, and then relapsing.

(Tobacco Control 2008;17:e3) http://tc.bmj.com/cgi/reprint/17/2/e3

Tobacco Control 2008;17:75 